\title{
PENGARUH KUALITAS LAYANAN TERHADAP KEPUASAN PELANGGAN DAN LOYALITAS PELANGGAN
}

\author{
(Studi pada Perpustakaan Institut Pertanian Bogor) \\ Fery Siswadi ${ }^{1 *}$, Hari Muharam ${ }^{2}$, Sufrin Hannan ${ }^{3}$ \\ ${ }^{1}$ Program Studi Manajemen, Program Pascasarjana Universitas Pakuan, Bogor \\ *) Email : mawar@apps.ipb.ac.id
}

\begin{abstract}
Abstrak
Penelitian ini bertujuan mengetahui pengaruh Kualitas Pelayanan terhadap Kepuasan Pelanggan dan Loyalitas Pelanggan. Penelitian ini di laksanakan di Perpustakaan Institut Pertanian Bogor (IPB) pada tahun 2018. Responden dalam penelitian ini adalah pengunjung Perpustakaan IPB yang telah lebih dari satu kali, Jumlah responden dalam penelitian ini ditetapkan 262 responden dengan menggunakan teknik pengambilan sampel yang disebut purposive sampling. Teknis analisis yang di gunakan pada Penelitian ini menggunakan analisis Structural Equation Modeling (SEM) dengan bantuan program LISREL 8.80. Hasil penelitian ini menunjukkan bahwa: Terdapat pengaruh positif langsung Kualitas Pelayanan terhadap Kepuasan. Terdapat Pengaruh positif langsung Kepuasan terhadap Loyalitas. Terdapat pengaruh positif langsung Kualitas Pelayanan terhadap Loyalitas. Terdapat pengaruh positif tidak langsung Kualitas Pelayanan berpengaruh terhadap Loyalitas.
\end{abstract}

Kata Kunci : kualitas pelayanan, kepuasan pelanggan, loyalitas pelanggan, perpustakaan, structural equation modeling (SEM), lisrel 8.80

\begin{abstract}
The purpose of study was to determine the effect of Service Quality on Customer Satisfaction and Customer Loyalty. This research was carried out in Bogor Agriculture University Library (IPB) in 2018. Respondents in this study were IPB library visitors who have more than one time, The number of respondents in this study set 262 respondents by using sampling technique called purposive sampling. Technical analysis used in this study using Structural Equation Modeling (SEM) analysis with the belp of LISREL 8.80 program. The results of this study indicate that: There is a direct positive effect Direct Service Quality directly affects the Satisfaction. There is a direct positive Influence Satisfaction on Loyalty. There is a direct positive effect of Quality of Service on Loyalty. There is an indirect positive influence Quality of Service affect Loyalty.
\end{abstract}

Keywords: service quality, customer satisfaction, customer loyalty, library, structural equation modeling (SEM), lisrel 8.80

\section{PENDAHULUAN}

Kebutuhan pelanggan menjadi hal yang sangat penting diperhatikan dalam rangka memberikan kepuasan bagi para pelanggan. Kehidupan mahasiswa tidak akan lepas dari perpustakaan, tugas-tugas seperti skripsi, tesis, disertasi tentunya sangat membutuhkan materi rujukan dari perpustakaan.

Perpustakaan pada perguruan tinggi merupakan salah satu institusi yang mendukung terlaksananya kegiatan belajar mengajar dan riset dengan cara mengelola dan penyebaran luaskan informasi bagi sivitas akademikanya.
Perpustakaan IPB telah berusaha meningkatkan kualitas pelayanan dan fasilitasnya, namun peningkatan kualitas layanan tersebut tidak diimbangi dengan meningkatnya jumlah pengguna perpustakaan.

Perpustakaan IPB melayani sivitas akademikanya, pengguna perpustakaan adalah sivitas akademik yang mendaftarkan diri keperpustakaan anggota perpustakaan. anggota perpustakaan sampai saat ini berjumlah 27.468, yang terdiri dari Mahasiswa S1 sebanyak 21.966 orang, S2 sebanyak 4.492, S3 sebanyak 414 orang, Staf Pengajar sebanyak 441 oarang dan Staf Administrasi 155 orang. 
Di tahun 2017 jumlah anggota perpustakaan yang berkunjung ke Perpustakaan berjumlah 196.883, jika dilihat rata-rata kunjungan mahasiswa pertahun hanya 7.2.

Kualitas pelayanan perpustakaan dapat ditentukan dari apakah harapan dan kebutuhan pengguna dapat terpenuhi. Oleh karenanya kualitas pelayanan merupakan salah satu variabel yang menentukan tercapainya kepuasan dan berdampak pada loyalitas pengguna dalam memanfaatkan layanan perpustakaan.

Kepuasan pelanggan menjadi salah satu tujuan utama dan sangat penting pada bidang jasa khususnya perpustakaan dalam menjaga hubungan jangka panjang dengan pelanggannya.

Menurut Fitsimmons (2014:144) Terciptanya kepuasan pelanggan terhadap suatu layanan diidentifikasikan melalui perbandingan antara persepsi terhadap layanan dengan harapan pelanggan.

Kepuasan dihasilkan dari akumulasi pelanggan setelah menggunakan layanan. Apabila pelanggan berfikir positif terhadap suatu layanan akan menghasilkan kepercayaan pelanggan untuk terus menggunakan layanan dan menyarankan orang lain untuk datang ketempat yang sama, pola pikir positif pelanggan pada perpustakaan akan menghasilkan komitmen untuk kembali ke perpustakaan dan merekomendasikan kepada orang lain (Akbar. 2009:24)

Terdapat banyak faktor yang mengakibatkan penurunan jumlah pengguna perpustakaan IPB, baik dari Internal perpustakaan maupun dari Eksternal. Atas dasar tersebut maka penulis meneliti berbagai hubungan yang menjadi kendala dari Perpustakaan dalam memberikan layanan bagi penggunanya dengan judul penelitian "Pengaruh kualitas pelayanan terhadap kepuasan dan loyalitas pengunjung Perpustakaan".

\section{TINJAUAN PUSTAKA}

\section{Loyalitas Pelanggan}

Loyalitas atau kesetiaan diartikan sebagai komitmen kuat dari pelanggan untuk membeli atau berlangganan produk/jasa tertentu di masa depan meskipun ada pengaruh situasi dan usaha pemasaran yang berpotensi merubahan perilaku (Kotler, 2009, hlm.175).

Loyalitas pelanggan perpustakaan tidak akan ada jika manajemen perpustakaan hanya meningkatkan kualitas layanan perpustakaan. I Gede Mahatma, et al. (2013).

Faktor loyalitas ditinjau melalui dua dimensi yaitu dimensi Kepuasan (Satisfaction) dan dimensi pembelian ulang (Retention). (Bagram, 2012). Menurut Marshall and Johnston (2015, hlm.185) menyatakan bahwa konsumen tidak akan beralih ke produk lain dan akan melakukan pembelian atau berkunjung kembali untuk menggunakan produk/jasa yang ditawarkan perusahaan. Supriadi (2011, hlm.24-25)

Loyalitas pelanggan didapat dari hasil pengukuran kepuasan dan ketidak puasan pelanggan, jika persepsi pelanggan terhadap layanan yang diberikan rendah, maka pelanggan akan berpindah ke tempat lain kecuali terdapat faktor lain yang kuat untuk pelanggan kembali. Apabila pelanggan puas dengan layanan yang diberikan dipastikan pelanggan akan kembali dan merekomendasikan kepada yang lain. (Cristobal, 2018).

Indikator yang mempengaruhi loyalitas pelanggan diantaranya : Kepuasan setelah membeli atau menggunakan produk/jasa, Kepercayaan secara emosional atau rasional terhadap organisasi, Kesedian untuk berkunjung kembali pada waktu-waktu yang akan datang, Merekomendasikan layanannya kepada orang lain, Melakukan pembelian secara teratur, Menunjukan kekebalan dari daya tarik produk sejenis dari pesaing

\section{Hakikat Kepuasan Pelanggan}

Menurut Kotler (2000, hlm.36-38)
"Satisfaction is a person's feelings of pleasure or
disappointment resulting from comparing a product
received performance (or outcome) in relation to his or her expectations." Menurut Fitzsimmons (2014, hlm.8083) "Satisfaction is the consumer's fulfillment response. It is a judgement that the product or service feature, or the product or service itself, provides a pleasurable level of consumption-related fulfillment'Artinya pelanggan akan merasa senang atau kecewa setelah membandingkan kinerja yang diterima dengan harapan.

"Customer Satisfaction is defined as "meet the expectation of customer". Baines, et al (2011, hlm.580-581.). Jika harapan terpenuhi maka kepuasan pelanggan tercapai. Kepuasan merupakan tingkat perasaan di mana seseorang menyatakan hasil perbandingan atas kinerja produk/jasa yang diterima dan yang diharapkan (Lupiyoadi. 2001, hlm.192). Faktor Yang mempengaruhi kepuasan : (1) Kualitas produk; (2) Kualitas pelayanan atau jasa, (3) Emosi, (4) Biaya. Sesuai dengan penyataan Hendy (2004, hlm.37) Kepuasan pelanggan merupakan dorongan dari faktor kualitas produk, harga yang sensitif, kualitas pelayanan yang baik, faktor emosi, biaya dan kemudahan dalam mendapatkan 
produk dan jasa. Zeithaml, (2009, hlm.85) menyatakan bahwa kepuasan pelanggan adalah evaluasi pelanggan terhadap produk atau jasa yang diterima apakah sesuai dengan kebutuhan dan harapan pelanggan.

Kepuasan Pelanggan adalah Penilaian pelanggan dari kesesuain kinerja dari apa yang diterima dengan apa yang diharapankan. Faktor yang yang mempengaruhi kepuasan antara lain : Persepsi pelanggan terhadap layanan, Dukungan layanan dan sistem, Pengalaman menggunakan layanan, Faktor situasi dan faktor pribadi dari pelanggan.

\section{Kualitas Pelayanan}

Menurut Kotler (2000, hlm.438) Kualitas Layanan (Service Quality) adalah perbandingan dari kualitas yang diterima pelanggan (perceived quality), yaitu setelah pelanggan menerima layanan, dengan kualitas yang diharapkan (expected quality). Artinya jika layanan yang diterima memiliki nilai lebih rendah dari pada layanan yang diharapkan, maka keinginan (interest) pelanggan akan berkurang. Persepsi pelanggan terhadap layanan yang kualitas terbentuk karena adanya perbedaan antara layanan yang diterima dengan layanan yang diharapkan. Menurut Baines (2011, hlm.503).

Kualitas layanan (Service Quality) merupakan persepsi pelanggan terhadap perbedaan antara layanan yg diterima dibandingkan dengan layanan yg diharapkan. Menurut Flora Han (2000, hlm.88) Kualitas layanan (service Quality) merupakan harapan pelanggan terhadap layanan dipengaruhi, secara eksternal, oleh komunikasi dari mulut ke mulut dan secara internal oleh pelanggan kebutuhan pribadi dan pengalaman masa lalu. Persepsi pelanggan akan kualitas layanan tergantung pada persepsi kinerja layanan aktual dibandingkan dengan harapan akan kinerja layanan yang seharusnya.

Parasuraman dalam Zethaml et.al (2009, hlm.87) mengungkapkan bahwa kualitas pelayanan adalah persepsi penyedia layanan yang keluar secara teknis, proses dimanahasilnya tercapai dan kualitas keseluruhan fisik layanan yang diberikan. Dalam membentuk penilaian kualitas layanan, yang didasarkan pada perbandingan antara layanan yang diharapkan dan yang dirasakan dapat menggunakan lima dimensi service quality yaitu : Keandalan (realiibility), Ketanggapan (responsiveness), Keyakinan (Assurance), Empati (Empatby) dan Berwujud (Tangibles).

Penggunaan lima dimensi Service Quality untuk membentuk penilaian kualitas pelayanan yang didasarkan pada perbandingan antara layanan yang diharapkan dan yang dirasakan
(Fitzsimmons. 2014, hlm.145). Kualitas layanan sebagai ukuran seberapa bagus tingkat layanan yang diberikan mampu terwujud sesuai harapan pelanggan.

Pada lima dimensi servqual dimana dimensi Reliability dianggap sebagai elemen yang paling penting oleh pelanggan disusul Responsivness, Assurance, Empathy dan Tangible. Kualitas Layanan adalah keseluruhan dari persepsi dan perbandingan pelanggan terhadap kualitas pelayanan yang diterima pelanggan dengan layanan yang diharapkan. Kualitas pelayanan dapat diukur berdasar pada lima dimensi Servqual yaitu : Keandalan (reliability), Ketanggapan (responsiveness), Jaminan (Assurance), Empati (Empathy), Bukti fisik (Tangibles)

\section{KERANGKA PEMIKIRAN}

Berdasarkan uraian diatas maka penulis mencoba membuat kerangka pemikiran sebagai berikut bahwa Kualitas Pelayanan merupakan salah satu faktor penentu tingkat kepuasan pelanggan, dengan kata lain kualitas pelayanan yang dirasakan pengguna akan meningkatkan kepuasan pengguna perpustakaan. kualitas pelayanan juga menjadi faktor penentu loyalitas, jika pelayanan yang diberikan perpustakaan yang dirasakan baik, sudah barang tentu pengguna akan kembali berkunjung ke Perpustakaan IPB. Yang dijelaskan pada gambar dibawah ini :

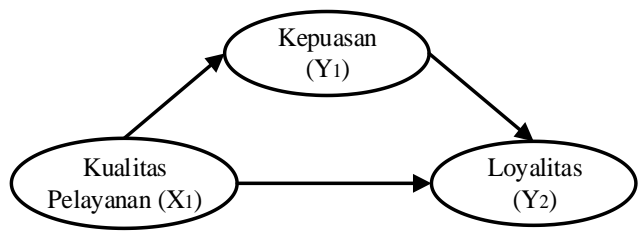

Gambar 1. Kerangka Pemikiran

Berdasarkan tujuan penelitian serta tinjauan penelitian terdahulu, maka hipotesis penelitian yang dapat dirumuskan adalah:

$\mathrm{H}_{1}$ : Terdapat pengaruh positif antara Kualitas pelayanan terhadap Kepuasan pelanggan di Perpustakaan.

$\mathrm{H}_{2}$ : Terdapat pengaruh positif antara Kepuasan pelanggan terhadap loyalitas pelanggan di Perpustakaan.

$\mathrm{H}_{3}$ : Terdapat pengaruh positif antara Kualitas Pelayanan Terhadap loyalitas pelanggan di Perpustakaan.

$\mathrm{H}_{4}$ : Terdapat pengaruh positif antara Kualitas Pelayanan terhadap loyalitas pelanggan 
melalui kepuasan pelanggan di Perpustakaan.

\section{METODE PENELITIAN}

Penelitian ini menggunakan metode Kausal yang bertujuan untuk mengetahui hubungan korelasi antar varibel kualitas pelayana, kepuasan dan loyalitas pelanggan di Perpustakaan IPB. Menurut Rangkuti (2015, hlm.24) Tujuan riset kausal adalah mencari hubungan antara sebab dan akibat untuk mengetahui variabel yang menjadi penyebab atau variabel pengaruh (variabel independen) dan variabel yang menjadi akibat atau variabel pengaruh (variabel dependen) dan mengetahui hubungan atau keterkaitan antara variabel-variabel tersebut.

\section{Populasi dan sampel}

Populasi dalam penelitian ini adalah pengguna perpustakaan yang berkunjung ke Perpustakaan. Data populasi diambil dari pengunjung Perpustakaan IPB. yang melakukan kunjungan lebih dari lima kali di tahun 2017 yaitu sebanyak 9.114 orang dibagi 12 bulan (Januari Desember) dan didapat populasi sebesar 760 . Kemudian populasi tersebut dihitung berdasarkan rumus solvin sebagai berikut:

Dimana :

$$
n=\frac{N}{1+N e^{2}}
$$

$\mathrm{n}=$ Besarnya Sampel $\mathrm{N}=$ Besarnya Populasi

e $=$ Persen kelonggaran ketidaktelitian karena kesalahan pengambilan sampel

Nilai e ditetapkan 5\% atau 0,05 sehingga penelitian berdasarkan rumus nilai $\mathrm{n}$ didapat sebagai berikut :

$$
n=\frac{760}{1+760(0.05)^{2}}=262 \text { orang }
$$

\section{Teknik Pengumpulan data}

Penelitian ini menggunakan sampel nonprobalitas yaitu teknik pengambilan sampel yang tidak memberikan peluang atau kesempatan yang sama pada setiap populasi yang terpilih menjadi sample (Sugiono, 2013, hlm.84). Penentuan sampel nonprobalitas yang dipilih menggunakan teknik Purposive sampling. Purposive sampling yaitu teknik penentuan sampel dengan pertimbangan tertentu (Sugiono, 2013, hlm.85).

\section{Metode Analisis}

Dalam penelitian ini Uji Validitas dan Reliabilitas menggunakan bantuan SPSS 23, sedangkan untuk menguji model dan hipotesis menggunakan analisis SEM (Struktural Equetion Modeling) dengan Program LISREL (Linear
Structural Relationship). SEM adalah Gabungan dua metode yang terpisah yaitu faktor dan model persaman simultan (Ghozali, 2008, hlm.3).

\section{HASIL DAN PEMBAHASAN}

\section{Karakteristik Responden}

Pada penelitian ini data responden diperoleh dari kuesioner yang di sebarkan pada responden yaitu pengunjung perpustakaan IPB yang telah mengunjungi perpustakaan lebih dari satu kali yaitu sebanyak 262 responden

\begin{tabular}{|c|c|c|c|}
\hline \multirow{2}{*}{$\begin{array}{c}\text { Jenis } \\
\text { Kelamin }\end{array}$} & \multirow{2}{*}{ Klasifikasi } & \multicolumn{2}{|c|}{ Jumlah reponden } \\
\hline & & Orang & $\%$ \\
\hline \multirow{3}{*}{$\begin{array}{l}\text { Jenis } \\
\text { Kelamin }\end{array}$} & Laki-laki & 117 & 44,7 \\
\hline & Perempuan & 145 & 55,3 \\
\hline & Total & 262 & 100 \\
\hline \multirow{4}{*}{ Usia } & $17-25$ tahun & 204 & 77,9 \\
\hline & $26-35$ tahun & 42 & 16 \\
\hline & $36-45$ tahun & 16 & 6,1 \\
\hline & Total & 262 & 100 \\
\hline \multirow{4}{*}{ Pekerjaan } & Dosen & 15 & 5,7 \\
\hline & Mahasiswa & 246 & 93,9 \\
\hline & Karyawan & 1 & 0,4 \\
\hline & Total & 262 & 100 \\
\hline \multirow{4}{*}{$\begin{array}{c}\text { Jenjang } \\
\text { Pendidikan }\end{array}$} & S1 & 159 & 60,7 \\
\hline & S2 & 74 & 28,2 \\
\hline & S3 & 29 & 11,1 \\
\hline & Total & 262 & 100 \\
\hline
\end{tabular}

Tabel 1. Karakteristik Responden

Sumber : Data Primer diolah 2018

\section{Hasil Pengujian Instrumen}

\section{Uji Validitas}

Uji validitas dilakukan pada 30 responden yaitu pengunjung perpustakaan IPB dengan ketentuan

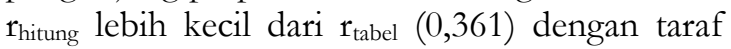
signifikansi $5 \%$.

Tabel 2. Hasil Uji Validitas

\begin{tabular}{|l|c|c|c|}
\hline Variabel & $\begin{array}{c}\text { Jumlah } \\
\text { item yang } \\
\text { diuji }\end{array}$ & $\begin{array}{c}\text { Jumlah } \\
\text { item tidak } \\
\text { valid }\end{array}$ & $\begin{array}{c}\text { Jumlah } \\
\text { item } \\
\text { valid }\end{array}$ \\
\hline $\begin{array}{l}\text { Kualitas } \\
\text { Pelayanan }\end{array}$ & 40 & 4 & 36 \\
\hline $\begin{array}{l}\text { Kepuasan } \\
\text { Pelanggan }\end{array}$ & 40 & 10 & 30 \\
\hline $\begin{array}{l}\text { Loyalitas } \\
\text { pelanggan }\end{array}$ & 40 & 7 & 33 \\
\hline
\end{tabular}

Sumber : Data Primer diolah 2018

\section{Uji Reliabilitas}

Dari hasil Pengujian Reliabilitas yang dilakukan terhadap 30 responden dimana reliabilitas variabel dikatakan baik apabila memiliki nilai cronbach's alpha lebih dari 0,60 (Wiyono, 2011).

Tabel 3. Hasil Uji Reliabilitas

\begin{tabular}{|l|l|} 
Variabel & cronbach's alpha
\end{tabular}




\begin{tabular}{|l|l|}
\hline Kualitas Pelayanan & 0,939 \\
\hline Kepuasan Pelanggan & 0,909 \\
\hline Loyalitas pelanggan & 0,933 \\
\hline
\end{tabular}

Sumber : Data Primer diolah 2018

\section{Hasil Uji analisis Structural Equation Modeling (SEM)}

Dalam pengujian dengan menggunakan Structural Equation Modeling (SEM) estimasi dilakukan secara bertahap. Pertama adalah melakukan Confirmatory Factor Analysis dan yang kedua dengan menggunakan Full Structural Equation Model.

1. Confirmatory Factor Analysis (CFA) Variabel Kualitas Pelayanan

Berdasarkan standard loading pada varibel Kualitas pelayanan di dapat hasil yang disajikan pada Tabel 4 :

Tabel 4. Goodness of Fit Kualitas Pelayanan (X)

\begin{tabular}{|c|c|c|c|}
\hline $\begin{array}{l}\text { Goodness- } \\
\text { of-Fit }\end{array}$ & $\begin{array}{l}\text { Cutt-off- } \\
\text { Value }\end{array}$ & Hasil & Kesimpulan \\
\hline $\begin{array}{c}\mathrm{X}^{2} \text { - Chi- } \\
\text { square }\end{array}$ & $\begin{array}{c}\text { Diharapkan } \\
\text { kecil }\end{array}$ & 3171.98 & \multirow{2}{*}{ poor fit } \\
\hline Significance & $\geq 0.05$ & $\mathrm{P}=0.00000$ & \\
\hline RMSEA & $\leq 0.08$ & 0.130 & poor fit \\
\hline GFI & $\geq 0.90$ & 0.880 & poor fit \\
\hline AGFI & $\geq 0.90$ & 0.860 & poor fit \\
\hline NFI & $\geq 0.90$ & 1.000 & $\begin{array}{c}\text { goodness } \\
\text { of fit }\end{array}$ \\
\hline NNFI & $\geq 0.90$ & 1.060 & $\begin{array}{c}\text { goodness } \\
\text { of fit }\end{array}$ \\
\hline CFI & $\geq 0.90$ & 1.000 & $\begin{array}{c}\text { goodness } \\
\text { of fit }\end{array}$ \\
\hline
\end{tabular}

Sumber : Data Primer diolah 2018

Berdasarkan Tabel 4.4, terdapat 4 kriteria goodness of fit tidak sesuai dengan cut off nya, sehingga untuk meningkatkan kesesuaian model, maka dilakukan modifikasi model dengan melakukan korelasi antar error indikator sesuai dengan petunjuk pada modification indices.

\section{a. Uji validitas Kualitas Pelayanan}

Tabel 5. Hasil Uji Validitas Kualitas Pelayanan (X)

\begin{tabular}{clccc}
\hline Laten & $\begin{array}{c}\text { Konstruk/ } \\
\text { Indikator }\end{array}$ & LF & T & Keterangan \\
\hline \multirow{6}{*}{ Fisik } & X11 & 0.55 & 6.63 & Valid \\
& X12 & 0.49 & 6.64 & Tidak Valid \\
& X13 & 0.36 & 6.05 & Tidak Valid \\
& X14 & 0.48 & 6.64 & Tidak Valid \\
& X15 & 0.57 & 6.71 & Valid \\
& X16 & 0.58 & 6.84 & Valid \\
\hline \multirow{6}{*}{ Handal } & X17 & 0.55 & 8.77 & Valid \\
& X18 & 0.69 & 9.04 & Valid \\
& X19 & 0.49 & 8.18 & Tidak Valid \\
& X110 & 0.64 & 9.06 & Valid \\
& X111 & 0.36 & 7.68 & Tidak Valid \\
& X112 & 0.43 & 8.27 & Tidak Valid \\
& X113 & 0.34 & 7.67 & Tidak Valid
\end{tabular}

\begin{tabular}{clccc}
\hline Laten & $\begin{array}{c}\text { Konstruk/ } \\
\text { Indikator }\end{array}$ & LF & T & Keterangan \\
\hline & X114 & 0.75 & 9.57 & Valid \\
\hline \multirow{5}{*}{ Tanggap } & X115 & 0.85 & 21.15 & Valid \\
& X116 & 0.84 & 20.94 & Valid \\
& X117 & 0.58 & 17.88 & Valid \\
& X118 & 0.72 & 20.22 & Valid \\
& X120 & 0.67 & 19.68 & Valid \\
& X121 & 0.38 & 14.14 & Tidak Valid \\
\cline { 2 - 5 } Jaminan & X122 & 0.32 & 12.56 & Tidak Valid \\
& X123 & 0.35 & 6.76 & Tidak Valid \\
& X124 & 0.37 & 7.13 & Tidak Valid \\
& X125 & 0.52 & 7.63 & Valid \\
& X126 & 0.59 & 6.10 & Valid \\
& X127 & 0.66 & 8.19 & Valid \\
& X128 & 0.63 & 8.01 & Valid \\
& X129 & 0.36 & 7.44 & Tidak Valid \\
\hline & X130 & 0.65 & 10.03 & Valid \\
& X131 & 0.74 & 10.16 & Valid \\
& X132 & 0.83 & 10.19 & Valid \\
E133 & 0.46 & 8.88 & Tidak Valid \\
& X134 & 0.48 & 9.00 & Tidak Valid \\
& X135 & 0.6 & 10.04 & Valid \\
& X136 & 0.17 & 5.07 & Tidak Valid \\
\hline \multirow{5}{*}{ Empati }
\end{tabular}

Sumber : Data Primer diolah 2018

Hasil loading faktor dari kualitas pelayanan terdapat nilai belum memenuhi persyaratan standard loading faktor $\geq 0,50$. Indikator yang tidak valid harus dihilangkan dari model dengan harapan dapat memperbaiki model secara keseluruhan. Hasil goodness of Fit setelah di modifikasi ditunjukan pada Tabel 6. dibawah ini :

Tabel 6. Goodness of Fit setelah dimodikasi

\begin{tabular}{|c|c|c|c|}
\hline $\begin{array}{c}\text { Goodness-of- } \\
\text { Fit }\end{array}$ & $\begin{array}{c}\text { Cutt-off- } \\
\text { Value }\end{array}$ & Hasil & Kesimpulan \\
\cline { 1 - 3 } $\mathrm{X}^{2}$ - Chi-square & $\begin{array}{c}\text { Diharapkan } \\
\text { kecil }\end{array}$ & 674.66 & \multirow{2}{*}{ poor fit } \\
\hline Significance & $\geq 0.05$ & $\mathrm{P}=0.00000$ & \\
\hline RMSEA & $\leq 0.08$ & 0.127 & poor fit \\
\hline GFI & $\geq 0.90$ & 0.960 & goodness of fit \\
\hline AGFI & $\geq 0.90$ & 0.950 & goodness of fit \\
\hline NFI & $\geq 0.90$ & 1.000 & goodness of fit \\
\hline NNFI & $\geq 0.90$ & 1.030 & goodness of fit \\
\hline CFI & $\geq 0.90$ & 1.000 & goodness of fit \\
\hline
\end{tabular}

Sumber : Data Primer diolah 2018

Dari Tabel 6 diketahui bahwa model menjadi lebih baik setelah indikator yang tidak valid dikeluarkan dari model, sehingga memenuhi kriteria goodness offit dan dinyatakan Baik, Menurut Hair et.all. (2010) dalam Latan (2012, hlm. 49) model dinyatakan fit jika memenuhi 4 - 5 kriteria Goodness of Fit (GOF) asalkan masing-masing kriteria absolute, incremental dan parsimony terpenuhi ini berarti model sudah fit, dan dapat mencerminkan variabel yang dianalisis. 
Langkah berikutnya melakukan Second Order Confirmatory Faktor Analysis. Analisis tingkat kedua ini menganalisis mengenai dimensi Kualitas pelayana dengan variabel Kualitas Pelayanan

\section{b. Uji Reliabilias Kualitas Pelayanan}

Tabel 7. Nilai Loading factor dan T-Value first order CFA Kualitas Pelayanan

\begin{tabular}{|c|l|c|c|c|c|}
\hline Laten & $\begin{array}{c}\text { Konstruk/ } \\
\text { Indikator }\end{array}$ & LF & T & Ket. & CR \\
\hline \multirow{4}{*}{$\begin{array}{c}\text { Pelaya } \\
\text { nan }\end{array}$} & Bukti Fisik & 0.89 & 3.78 & Valid & 0.89 \\
\cline { 2 - 6 } & Kehandalan & 0.94 & 2.01 & Valid & 0.90 \\
\cline { 2 - 6 } & Daya Tanggap & 0.68 & 15.00 & Valid & 0.82 \\
\cline { 2 - 6 } & Jaminan & 0.94 & 1.97 & Valid & 0.90 \\
\cline { 2 - 6 } & Empati & 0.96 & 2.24 & Valid & 0.90 \\
\hline
\end{tabular}

Sumber : Data Primer diolah 2018

Pada pengujian loading factor di first order, didapatkan nilai LF semua berada diatas 0,5 sehingga semua indikator di first order sudah baik. Pada Pengujian Reabilitas Pelayanan menunjukkan pada nilai CR dari semua Indikatornya menunjukkan bahwa CR yang didapat $>0.70$ sehingga indicator-indikator yang terbentuk sudah baik untuk dilakukan pemodelan.

1. Confirmatory Factor Analysis (CFA) Variabel Kepuasan Pelanggan

Berdasarkan standard loading pada varibel Kepuasan Pelanggan di dapat hasil yang disajikan pada Tabel 8. :

Tabel 8. Goodness of Fit Kepuasan Pelanggan $\left(\mathrm{Y}_{1}\right)$

\begin{tabular}{|c|c|c|c|}
\hline $\begin{array}{c}\text { Goodness-of- } \\
\text { Fit }\end{array}$ & $\begin{array}{c}\text { Cutt-off- } \\
\text { Value }\end{array}$ & Hasil & Kesimpulan \\
\cline { 1 - 3 } X $^{2}$ - Chi-square & $\begin{array}{c}\text { Diharapkan } \\
\text { kecil }\end{array}$ & 47.6 & \multirow{2}{*}{ poor fit } \\
\hline Significance & $\geq 0.05$ & $\mathrm{P}=0.00000$ & \\
\hline RMSEA & $\leq 0.08$ & 0.296 & poor fit \\
\hline GFI & $\geq 0.90$ & 1.000 & goodness of fit \\
\hline AGFI & $\geq 0.90$ & 0.990 & goodness of fit \\
\hline NFI & $\geq 0.90$ & 1.000 & goodness of fit \\
\hline NNFI & $\geq 0.90$ & 1.010 & goodness of fit \\
\hline CFI & $\geq 0.90$ & 1.000 & goodness of fit \\
\hline
\end{tabular}

Sumber : Data Primer diolah 2018

Dari Tabel 8. menunjukan dari delapan kriteria, lima telah memenuhi kriteria goodness of fit dan dinyatakan Baik. Dari empat indikator dapat mencerminkan variabel laten yang dianalisis.

Tabel 9. Nilai Loading factor dan T-V alue first order CFA Kepuasan Pelanggan

\begin{tabular}{|c|l|c|c|c|c|}
\hline Laten & $\begin{array}{c}\text { Konstruk/ } \\
\text { Indikator }\end{array}$ & LF & T & Ket. & CR \\
\hline \multirow{4}{*}{$\begin{array}{l}\text { KEPU } \\
\text { ASAN }\end{array}$} & PP & 0.91 & 18.43 & Valid & \\
\cline { 2 - 5 } & DL & 0.88 & 18.16 & Valid & \multirow{2}{*}{0.91} \\
\cline { 2 - 5 } & PL & 0.85 & 17.96 & Valid & \\
\cline { 2 - 5 } & FS & 0.75 & 16.84 & Valid & \\
\hline
\end{tabular}

Sumber : Data Primer diolah 2018
Pada pengujian loading factor di first order, didapatkan nilai LF semua berada diatas 0,5 sehingga semua indikator di first order sudah baik. Pada Pengujian Reabilitas Kepuasan Pelanggan menunjukkan pada nilai CR dari semua Indikatornya menunjukkan bahwa CR yang didapat $0,91>0.70$ sehingga indikator-indikator yang terbentuk sudah baik untuk dilakukan pemodelan.

\section{Confirmatory Factor Analysis (CFA) Variabel Loyalitas Pelanggan}

Berdasarkan standard loading pada varibel Loyalitas Pelanggan di dapat hasil yang disajikan pada Tabel 10. :

Tabel 10. Goodness of Fit Loyalitas Pelanggan (Y2)

\begin{tabular}{|c|c|c|c|}
\hline $\begin{array}{c}\text { Goodness-of- } \\
\text { Fit }\end{array}$ & $\begin{array}{c}\text { Cutt-off- } \\
\text { Value }\end{array}$ & Hasil & Kesimpulan \\
\cline { 1 - 3 } $\mathrm{X}^{2}$ - Chi-square & $\begin{array}{c}\text { Diharapkan } \\
\text { kecil }\end{array}$ & 102.76 & \multirow{2}{*}{ poor fit } \\
\hline Significance & $\geq 0.05$ & $\mathrm{P}=0.00000$ & poor fit \\
\hline RMSEA & $\leq 0.08$ & 0.200 & goodness of fit \\
\hline GFI & $\geq 0.90$ & 0.990 & goodness of fit \\
\hline AGFI & $\geq 0.90$ & 0.980 & goodness of fit \\
\hline NFI & $\geq 0.90$ & 1.000 & goodness of fit \\
\hline NNFI & $\geq 0.90$ & 1.010 & goodness of fit \\
\hline CFI & $\geq 0.90$ & 1.000 &
\end{tabular}

Sumber : Data Primer diolah 2018

Dari tabel 4.10 menunjukan dari delapan kriteria, lima telah memenuhi kriteria goodness of fit dan dinyatakan Baik. Dari enam indikator dapat mencerminkan variabel laten yang dianalisis.

Tabel 11. Nilai Loading factor dan T-V alue first $\operatorname{order} C F A$ Loyalitas Pelanggan

\begin{tabular}{|c|l|c|c|c|c|}
\hline Laten & $\begin{array}{c}\text { Konstruk/ } \\
\text { Indikator }\end{array}$ & LF & $\mathbf{T}$ & Ket. & CR \\
\hline \multirow{4}{*}{$\begin{array}{c}\text { LOYA } \\
\text { LITAS }\end{array}$} & KP & 0.59 & 16.25 & Valid & \\
\cline { 2 - 5 } & KS & 0.62 & 20.98 & Valid & \\
\cline { 2 - 5 } & ML & 0.85 & 20.94 & Valid & \multirow{2}{*}{0.89} \\
\cline { 2 - 5 } & ML & 0.85 & 21.00 & Valid & \\
\cline { 2 - 5 } & MT & 0.85 & 21.06 & Valid & \\
\hline
\end{tabular}

Sumber : Data Primer diolah 2018

Pada pengujian loading factor di first order, didapatkan nilai LF semua berada diatas 0,5 sehingga semua indikator di first order sudah baik. Pada Pengujian Reabilitas Loyalitas Pelanggan menunjukkan pada nilai $C R$ dari semua Indikatornya menunjukkan bahwa CR yang didapat $0,89>0.70$ sehingga indikator-indikator yang terbentuk sudah baik untuk dilakukan pemodelan.

\section{Pengujian Hipotesis}

Berdasarkan tujuan penelitian yaitu untuk mengetahui pengaruh Kualitas Pelayanan (X) 
terhadap Kepuasan Pelanggan $\left(\mathrm{Y}_{1}\right)$ dan Loyalitas Pelanggan $\left(\mathrm{Y}_{2}\right)$ sesuai dengan kerangka penelitian. Model penuh persamaan Structural Equation
Modeling (SEM) dengan menggunakan Lisrel 8.80 dapat dilihat pada Gambar 5. dibawah ini :

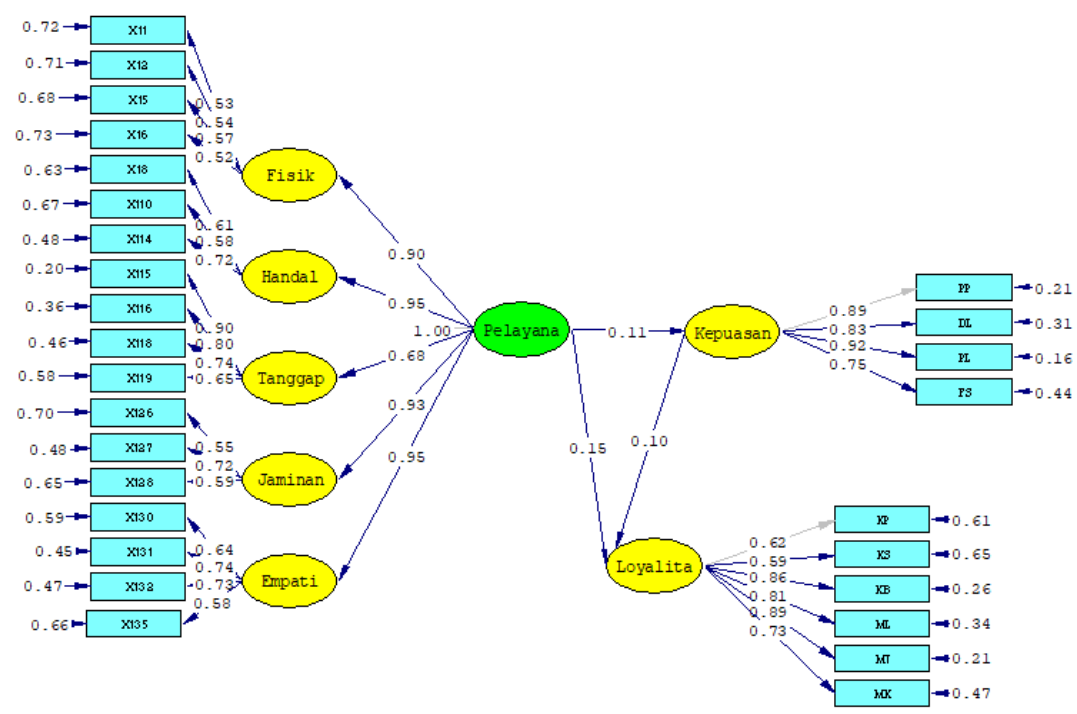

Chi-Square $=1567.69, \mathrm{df}=342, \mathrm{P}$-value $=0.00000, \mathrm{RMSEA}=0.117$

Gambar 5. Standar Loading Faktor Full Model

Hasil uji model disajikan pada Gambar 4.7 dan dievaluasi berdasarkan nilai goodness of fit pada Tabel 12, berikut disajikan kriteria model serta nilai kritisnya yang memiliki kesesuaian data.

Tabel 12. Evaluasi kriteria goodness of fit Full model

\begin{tabular}{|c|c|c|c|}
\hline $\begin{array}{l}\text { Goodness-of- } \\
\text { Fit }\end{array}$ & Cutt-off-Value & Hasil & Kesimpulan \\
\hline $\begin{array}{c}\mathrm{X}^{2}-\text { Chi- } \\
\text { square }\end{array}$ & $\begin{array}{c}\text { Diharapkan } \\
\text { kecil }\end{array}$ & 1567.69 & \multirow[t]{2}{*}{ poor fit } \\
\hline Significance & $\geq 0.05$ & $\mathrm{P}=0.00000$ & \\
\hline RMSEA & $\leq 0.08$ & 0.117 & poor fit \\
\hline GFI & $\geq 0.90$ & 0.940 & $\begin{array}{c}\text { goodness of } \\
\text { fit }\end{array}$ \\
\hline AGFI & $\geq 0.90$ & 0.930 & $\begin{array}{c}\text { goodness of } \\
\text { fit }\end{array}$ \\
\hline NFI & $\geq 0.90$ & 1.000 & $\begin{array}{c}\text { goodness of } \\
\text { fit }\end{array}$ \\
\hline NNFI & $\geq 0.90$ & 1.050 & $\begin{array}{c}\text { goodness of } \\
\text { fit }\end{array}$ \\
\hline
\end{tabular}

\begin{tabular}{|c|c|c|c|}
\hline $\begin{array}{c}\text { Goodness-of- } \\
\text { Fit }\end{array}$ & Cutt-off-Value & Hasil & Kesimpulan \\
\hline CFI & $\geq 0.90$ & 1.000 & $\begin{array}{c}\text { goodness of } \\
\text { fit }\end{array}$ \\
\hline
\end{tabular}

Sumber : Data Primer diolah 2018

Hasil pengolahan untuk pengujian goodness of fit menunjukkan dari lima kriteria dinyatakan baik dan dua dinyatakan kurang baik. Penggunaan kriteria goodness of fit yang lain yaitu GFI, AGFI, NFI, NNFI dan CFI menghasilkan nilai diatas Cutt-off value yang artinya model yang dihasilkan sudah goodness of fit. Karena hasil kesimpulan beberapa indikator menghasilkan kesimpulan model goodness of fit maka pengujian hipotesis teori dapat dilakukan. 


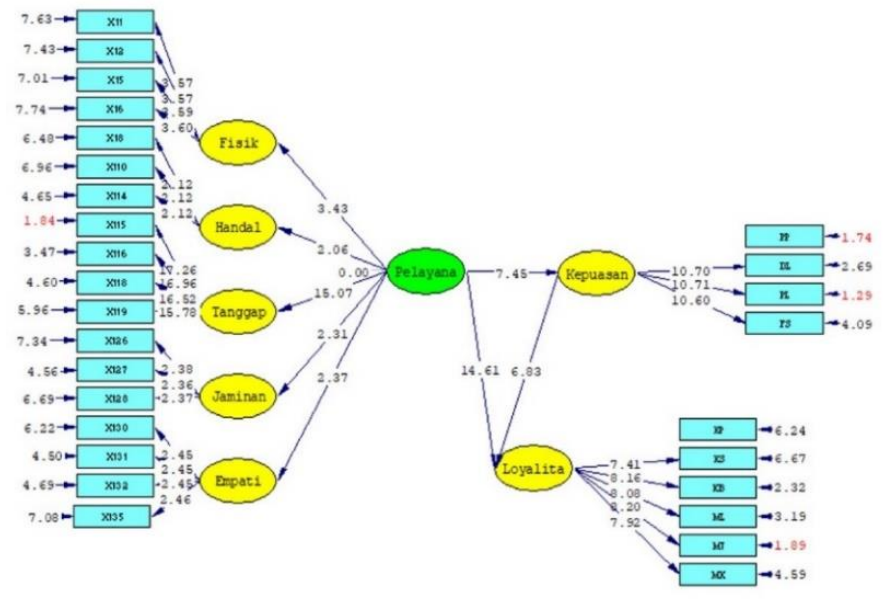

Ch1-Square $=1567.69$, df $=342, P$-value $=0.00000$, RMSEA $=0.117$

Gambar 6 Hasil t-value Full Model

Tabel 13. dibawah disajikan hubungan kausal antara variabel Kualitas Pelayanan,
Variabel Kepuasan Pelanggan dan Loyalitas Pelanggan.

Tabel 13. Uji Kesesuaian hubungan antar variabel Laten

\begin{tabular}{|c|c|c|c|c|}
\hline No. Deskripsi & Standardized loading factor/R & $\begin{array}{c}\text { t-value/ } \\
\text { v-value }\end{array}$ & Simpulan statistik \\
\hline \multicolumn{5}{|c|}{ Langsung } \\
\hline 1 & Kualitas Pelayanan -> Kepuasan & 0.11 & 7.45 & Signifikan \\
\hline 2 & Kepuasan Pelanggan -> Loyalitas Pelanggan & 0.10 & 6.83 & Signifikan \\
\hline 3 & Kualitas Pelayanan -> Loyalitas Pelanggan & 0.15 & 14.61 & Signifikan \\
\hline \multicolumn{5}{|c|}{ Tidak langsung } \\
\hline 4 & Kualitas Pelayanan -> Loyalitas Pelanggan & 0.01 & 5.46 & Signifikan \\
\hline
\end{tabular}

Sumber : Data Primer diolah 2018

Berdasarkan tabel diatas dapat dilihat bahwa semua hubungan terbukti signifikan, dimana dapat dilihat dari nilai t-value $>1,96$. Dari data diatas dapat disimpulkan untuk menjawab empat hipotesis pada penelitian ini. Hasil pengujian hipotesis disajikan pada Tabel 14.

Tabel 14. Hasil pengujian Hipotesis

\begin{tabular}{|c|l|c|c|c|}
\hline Hipotesis & \multicolumn{1}{|c|}{ Deskripsi } & $\begin{array}{c}\text { Standardized loading } \\
\text { factor/R }\end{array}$ & $\begin{array}{c}\text { t-value/ } \\
\text { v-value }\end{array}$ & Keterangan \\
\hline H1 & Kualitas Pelayanan -> Kepuasan & 0.11 & 7.45 & $\begin{array}{c}\text { Tolak } \mathrm{H}_{0} \\
\text { Terima } \mathrm{H}_{1}\end{array}$ \\
\hline H2 & Kepuasan Pelanggan -> Loyalitas Pelanggan & 0.10 & 6.83 & $\begin{array}{c}\text { Tolak } \mathrm{H}_{0} \\
\text { Terima } \mathrm{H}_{2}\end{array}$ \\
\hline H3 & Kualitas Pelayanan -> Loyalitas Pelanggan & 0.15 & 14.61 & $\begin{array}{c}\text { Tolak } \mathrm{H}_{0} \\
\text { Terima } \mathrm{H}_{3}\end{array}$ \\
\hline H4 & $\begin{array}{l}\text { Kualitas Pelayanan -> Kepuasan -> Loyalitas } \\
\text { Pelanggan }\end{array}$ & 0.01 & 5.46 & $\begin{array}{c}\text { Tolak } \mathrm{H}_{0} \\
\text { Terima } \mathrm{H}_{4}\end{array}$ \\
\hline
\end{tabular}

Sumber : Data Primer diolah 2018

\section{PEMBAHASAN}

Analisis pada penelitian ini digunakan untuk mengetahui pengaruh Kualitas Pelayanan $\left(\mathrm{X}_{1}\right)$ terhadap Kepuasan Pelanggan $\left(\mathrm{Y}_{1}\right)$ dan Loyalitas Pelanggan $\left(\mathrm{Y}_{2}\right)$ sesuai dengan identifikasi masalah maka pengujian hipotesis ini dibagi dalam empat bagian yaitu Pengaruh kualitas pelayanan terhadap kepuasan pelanggan di Perpustakaan
IPB, Pengaruh Kepuasan terhadap Loyalitas pelanggan di Perpustakaan IPB, Pengaruh kualitas pelayanan terhadap Loyalitas pelanggan di Perpustakaan IPB dan Pengaruh Kualitas Pelayanan terhadap Loyalitas Pelanggan melalui Kepuasan Pelanggan di Perpustakaan IPB.
$\mathrm{H}_{1}$ : Terdapat Pengaruh Signifikan antar kualitas pelayanan terhadap kepuasan pelanggan


Hasil analisis statistik menunjukan menyatakan Kualitas pelayanan berpengaruh positif langsung terhadap Kepuasan. Dari hasil pengolahan diperoleh koefisien estimasi sebesar 0.11 yang artinya semakin tinggi Pelayanan akan semakin tinggi Kepuasan secara langsung dan sebaliknya. Hasil ini menunjukkan bahwa hipotesis teori yang diajukan terbukti dengan nilai tsatistik sebesar $7.45>$ t-table 1.96 yang artinya Ho ditolak sehingga dapat disimpulkan bahwa terdapat pengaruh positif dari Pelayanan terhadap Kepuasan. Hasil ini sesuai dengan penelitian yang dilakukan oleh Wantara (2015) yang menyimpulkan bahwa kualitas layanan mungkin menjadi faktor paling signifikan yang mempengaruhi kepuasan pelanggan. Hasil penelitian Sufrin, et al (2016) menyimpulkan menunjukkan bahwa kepuasan pelanggan dipengaruhi oleh kualitas yang dirasakan, nilai yang dirasakan dan harapan pelanggan. Ismail (2016) Hasil dari analisis model jalur menunjukkan bahwa dimensi kualitas layanan, yaitu nyata, keandalan, daya tanggap, jaminan dan empati secara signifikan berkorelasi dengan kepuasan pelanggan ini menegaskan bahwa kemampuan penyedia layanan untuk secara tepat menerapkan dimensi kualitas dalam memberikan layanan medis telah meningkatkan kepuasan pelanggan dalam organisasi.

\section{H2 : Terdapat Pengaruh Signifikan antar kepuasan pelanggan terhadap Loyalitas pelanggan}

Dari hasil pengolahan diperoleh koefisien estimasi sebesar 0.10 yang artinya semakin tinggi Kepuasan akan semakin tinggi Loyalitas secara langsung dan sebaliknya. Hasil ini menunjukkan bahwa hipotesis teori yang diajukan terbukti dengan nilai tsatistik sebesar $6.83>$ t-table 1.96 yang artinya Ho ditolak sehingga dapat disimpulkan bahwa terdapat pengaruh positif dari Kepuasan terhadap Loyalitas. Senada dengan penelitian Y. Nurendah (2013) yang menyimpulkan Variabel kepuasan mahasiswa dapat menjelaskan variabilitas loyalitas mahasiswa dengan tingkat sedang yaitu sebesar 43,29\%. Kepuasan mahasiswa memiliki hubungan yang positif dan signifikan dengan loyalitas mahasiswa. Senada dengan hasil penelitian Gusti ayu (2014) analisis data secara statistik membuktikan bahwa terdapat pengaruh positif dan signifikan antara kepuasan terhadap loyalitas, semakin baik kepuasan yang dirasakan maka akan semakin tinggi loyalitas, sebaliknya bila kepuasan yang dirasakan rendah, maka loyalitas juga akan semakin rendah. Penelitian yang dilakukan Hussen (2015). Menunjukkan bahwa secara keseluruhan kepuasan pelanggan secara signifikan dan berhubungan positif dengan loyalitas pelanggan.

\section{H3 : Terdapat Pengaruh Signifikan antar Kualitas Pelayanan terhadap Loyalitas pelanggan}

Dari hasil pengolahan diperoleh Pelayanan berpengaruh positif langsung terhadap Loyalitas. Dari hasil pengolahan diperoleh koefisien estimasi sebesar 0.15 yang artinya semakin tinggi Pelayanan akan semakin tinggi Loyalitas secara langsung dan sebaliknya. Hasil ini menunjukkan bahwa hipotesis teori yang diajukan terbukti dengan nilai tsatistik sebesar $14.61>$ t-table 1.96 yang artinya Ho ditolak sehingga dapat disimpulkan bahwa terdapat pengaruh positif dari Pelayanan terhadap Loyalitas.. Hasil penelitian Gusti ayu (2014) data secara statistik membuktikan bahwa kualitas pelayanan berpengaruh positif dan signifikan terhadap loyalitas, Semakin baik kualitas pelayanan maka semakin tinggi pula loyalitas yang diperoleh, sebaliknya semakin buruk kualitas pelayanan maka semakin rendah pula loyalitas. Hasil penelitian ini sesuai dengan penelitian yang dilakukan oleh Akbar (2009) menjunjukkan terdapat hubungan yang positif dan signifikan antara kualitas pelayanan terhadap loyalitas pelanggan

\section{H4 : Terdapat Pengaruh Signifikan antar Kualitas Pelayanan terhadap Loyalitas pelanggan melalui Kepuasan pelanggan}

Dari hasil pengolahan Pelayanan berpengaruh positif tidak langsung terhadap Loyalitas. Dari hasil pengolahan diperoleh koefisien estimasi sebesar 0.010 yang artinya semakin tinggi Pelayanan akan semakin tinggi Loyalitas secara tidak langsung dan sebaliknya. Hasil ini menunjukkan bahwa hipotesis teori yang diajukan terbukti dengan nilai tsatistik sebesar $5.46>$ t-table 1.96 yang artinya Ho ditolak sehingga dapat disimpulkan bahwa terdapat pengaruh positif dari Pelayanan terhadap Loyalitas secara tidak langsung. Besaran pengaruh tidak langsung kualitas pelayanan terhadap loyalitas melalui kepuasan pelanggan adalah sebesar 5.46. Ini berarti bahwa, kepuasan dapat menjadi variabel intervening antara kualitas pelayanan dan loyalitas. Hal tersebut menunjukkan bahwa tingkat kepuasan juga perlu diperhatikan dalam upaya memperoleh loyalitas. Hasil yang sama dengan penelitian Wantara (2015) bahwa kualitas pelayanan dan kepuasan pelanggan secara signifikan dan berhubungan 
positif dengan loyalitas pelanggan. Kualitas layanan mungkin menjadi faktor paling signifikan yang mempengaruhi kepuasan pelanggan. Kemudian, kualitas layanan dapat dianggap sebagai penentu kepuasan, dan pengaruhnya terhadap loyalitas dimediasi oleh kepuasan.

\section{KESIMPULAN}

Berdasarkan hasil penelitian dan pembahasan mengenai Pengaruh Kualitas pelayanan terhadap Kepuasan Pelanggan dan Loyalitas Pelanggan dapat ditarik kesimpulan sebagai berikut :

1. Terdapat pengaruh positif langsung Kualitas Pelayanan terhadap Kepuasan. Dari hasil pengolahan diperoleh koefisien estimasi sebesar 0.11 yang artinya semakin tinggi Pelayanan akan semakin tinggi Kepuasan secara langsung dan sebaliknya. Hasil ini menunjukkan bahwa hipotesis teori yang diajukan terbukti dengan nilai tsatistik sebesar $7.45>$ t-table 1.96 yang artinya $\mathrm{Ho}$ ditolak sehingga dapat disimpulkan bahwa terdapat pengaruh positif dari Pelayanan terhadap Kepuasan.

2. Terdapat Pengaruh positif langsung Kepuasan terhadap Loyalitas. Dari hasil pengolahan diperoleh koefisien estimasi sebesar 0.10 yang artinya semakin tinggi Kepuasan akan semakin tinggi Loyalitas secara langsung dan sebaliknya. Hasil ini menunjukkan bahwa hipotesis teori yang diajukan terbukti dengan nilai tsatistik sebesar $6.83>$ t-table 1.96 yang artinya Ho ditolak sehingga dapat disimpulkan bahwa terdapat pengaruh positif dari Kepuasan terhadap Loyalitas.

3. Terdapat pengaruh positif langsung Kualitas Pelayanan terhadap Loyalitas. Dari hasil pengolahan diperoleh koefisien estimasi sebesar 0.15 yang artinya semakin tinggi Pelayanan akan semakin tinggi Loyalitas secara langsung dan sebaliknya. Hasil ini menunjukkan bahwa hipotesis teori yang diajukan terbukti dengan nilai tsatistik sebesar $14.61>$ t-table 1.96 yang artinya $\mathrm{Ho}$ ditolak sehingga dapat disimpulkan bahwa terdapat pengaruh positif dari Pelayanan terhadap Loyalitas.

4. Terdapat pengaruh positif tidak langsung Kualitas Pelayanan berpengaruh terhadap Loyalitas. Dari hasil pengolahan diperoleh koefisien estimasi sebesar 0.010 yang artinya semakin tinggi Pelayanan akan semakin tinggi Loyalitas secara tidak langsung dan sebaliknya. Hasil ini menunjukkan bahwa hipotesis teori yang diajukan terbukti dengan nilai tsatistik sebesar $5.46>$ t-table 1.96 yang artinya Ho ditolak sehingga dapat disimpulkan bahwa terdapat pengaruh positif dari Pelayanan terhadap Loyalitas secara tidak langsung.

\section{SARAN}

Berdasarkan uraian dari kesimpulan dan implikasi yang telah diuraikan diatas, maka penulis mengajukan beberapa saran terutama yang berkaitan dengan upaya peningkatan Kualitas pelayanan yang berdampak kepuasan pelanggan dan loyalitas

1. Kualitas pelayanan perpustkaan secara keseluruhan sudah sangat baik, namun masih harus diperhatikan adalah keahlian staf dalam memberikan informasi yang sesuai dengan keinginan pengguna Perpustakaan IPB

2. Meningkatkan sarana dan fasilitas pendukung seperti Hostpot, komputer, dan koleksi yang relevan

\section{DAFTAR PUSTAKA}

Akbar, M.M. and Parvez, N. 2009. "Impact of service quality, trust and customer satisfaction on customer loyalty”. ABAC Journal, Vol. 29 No. 1, pp. 24-38.

Anna Martensen dan Gronholdt. 2015. "Improving Library User's Perceived Quality, Satisfication and Loyalty: An Integrated Measurement and Management System. The Journal of Academic Librarianship, Volume 29, number 3, page 141

Arikunto, S. 2002. Prosedur penelitian suatu pendekatan praktek. Jakarta. Rineka Cipta.

Bagram M.M.M and Shahzad Khan. 2012. "Attaining Customer Loyalty! The Role of Consumer Attitude and Consumer Behavior". International Review of Management and Business Research, Vol. 1, Issue 1, Dec 2012, pp. 1-12

Baines, Paul., Chris Fiil \& Kelly Page. 2011. Marketing. New York: Oxford University Press

Cook, Collen [et.al]. LibQual+@ 2011 Survey Results. Washington D.C: Association of Research Libraries, 2011

Cristobal, Arlyn Selga. 2018. "Expectations on Library Services, Library Quality (LibQual) Dimension and Library Customer Satisfaction: Relationship to Customer Loyalty". Library Philosophy and Practice (e-journal). 1706. https: / / digitalcommons.unl.edu/ libphilprac/1706

Daryanto dan Ismanto Setyobudi. 2014. Konsumen dan Pelayanan Prima. Yogyakarta: Penerbit Gava Media. pp.127 
Desy Handayani et.al. 2009. Service operation. Tim Markplus, Jakarta : Erlangga, pp. 9-11

Fandy Tjiptono.2008. Strategi Pemasaran Ed. 3. Yogyakarta. Andi Pub. Pp. 175

Fatmawati, Endang. 2013. Mata Baru Penelitian Perpustakaan dari Servqual ke LibQual+TM. Jakarta : Sagung Seto

Ferdinand, A. 2002. Structural Equation Modeling dalam Penelitian Manajemen, Edisi ketiga, FakultasEkonomi UNDIP, Semarang

Firdaus M, Harmini, Farid MA. 2011. Aplikasi Metode Kuantitatif untuk Manajemen dan Bisnis. Bogor (ID): IPB Press.

Fitzsimmons, James A. 2014. Service management: operations, strategy, information technology / James. New York : McGraw Hill. Pp. 144145

Flora han and Debbie leong.2000. Produktivity and service Quality, Singapore: Prentice Hall.

Ghozali I. 2008. Structural Equation Modelling. Metode Alternatif dengan Partial Least Square. Edisi 2. Semarang: Badan Penerbit Universitas Dipenogoro.

Ghozali, Imam. 2005. Analisis Multi Variat dengan Program SPSS. Edisi Ketiga. Universitas Diponegoro, Semarang.

Griffin, Jill. 2003. Customer Loyalty : Menumbubkan Dan Mempertahankan Pelanggan. Jakarta, Airlangga

Gusti Ayu Putu Ratih Kusuma Dewi. 2014. Pengaruh Kualitas Pelayanan Terhadap Kepuasan dan Loyalitas Nasabah PT BPR Hoki di Kabupaten Tabanan. Denpasar. Universitas Udayana, Tesis

Hendy Irawan. 2004. Kepuasan Pelayanan Jasa. Erlangga. Jakarta. pp. 37

Hurriyati, Ratih. 2010. Bauran Pemasaran dan Loyalitas Konsumen. Bandung: ALFABETHA. pp. 128-130

Hussen, Shambachew. 2015. Service Quality, Customers' Satisfaction and Loyalty: A Study on Insurance Companies in Adama, Ethiopia Business and Economics Faculty, ISSN 22221905 (Paper) ISSN 2222-2839 (Online) Vol.7, No.4, 2015269

I Gede Mahatma Yuda Bakti and Sik Sumaedi. 2013. An analysis of library customer loyalty: The role of service quality and customer satisfaction, a case study in Indonesia . Library Management Vol. 34 No. 6/7, 2013 pp. 397414. Emerald Group Publishing Limited 01435124 DOI 10.1108/LM-05-2012-0025.

Indonesia, Perpustakaan Nasional RI. 1999. Pedoman Umum Pengelolaan koleksi perpustakaan Perguruan Tinggi. Jakarta : Perpustakaan Nasional RI bagian Proyek Pengembangan Sistem Nasional.
Ismail A., Yunan Y..M., 2016, Service quality as a predictor of customer satisfaction and customer loyalty. LogForum 12 (4), 269-283, DOI: 10.17270/J.LOG.2016.4.7 URL: http://www.logforum.net/vol12/issue4/n o7 Accepted: 28.10.2016, on-line: 11.11.2016.

Kementerian Hukum Dan Hak Asasi Manusia Republik Indonesia. 2007. Undang-Undang Republik Indonesia Nomor 43 Tabun 2007 Tentang Perpustakaan. Jakarta (ID): RI.

Kementerian Hukum Dan Hak Asasi Manusia Republik Indonesia. 2009. Undang-Undang Republik Indonesia Nomor 25 Tabun 2009 Tentang Pelayanan Publik. Jakarta (ID): RI.

KEPMENPAN \& RB. 2014. Peraturan Menteri Pendayagunaan Aparatur Negara dan Reformasi Birokrasi Nomor 16 Tahun 2014 Tentang Pedoman Survei Kepuasan Masyarakat Terhadap Penyelenggaraan Pelayanan Publik. Jakarta (ID): RI.

Kotler, P. 2000. Marketing Management. Upper Saddle River, NJ: Prentice Hall, pp. 438440

Kotler, P. dan Keller, K.L. 2007. Manajemen Pemasaran. Jilid 1 dan 2. Jakarta: PT Indeks.

Kotler, Philip dan Kevin Lane Keller. 2009a. Manajemen Pemasaran. Diterjemahkan oleh: Bob Sabran. Edisi 13. Jilid 1. Jakarta: Erlangga

Kottler and Kaller. 2009. Manajemen Pemasaran, Jilid 1 Edisi 13. Jakarta: Erlangga

Kuncoro, Mudrajad. 2003. Metode Riset untuk Bisnis dan Ekonomi Bagaimana Meneliti dan Menulis Tesis. Erlangga, Jakarta.

Ladhari, R., \& Morales, M. (2008). Perceived service quality, perceived value and recommendation. Library Management, 29(4), 352-366. Doi: http://dx.doi.org/10.1108/0143251208108 69129

Latan, Hengki. 2012. Structural Equation Modelling : Konsep dan aplikasi menggunakan Program Lisrel 8.80. Bandung : Alfabeta

Latan, Hengki. 2013. Model Persamaan Struktural : Teori dan Implementasi Amos 21.0. Bandung : Alfabeta

Lovelock, C.H dan Wright, L.K. 2007. Manajemen Pemasaran Jasa. Edisi Bahasa Indonesia. Jakarta: PT Indeks

Lupiyoadi, Rambat dan A. Hamdani, 2006. Manajemen Pemasaran Jasa, edisi 2. Jakarta: Salemba Empat

Marshall, GW \& M.W. Johnston. 2015. Marketing Management. New York: McGrawHill. p. 185

Martoatmojo, karmidi. 2011. Pelestarian Bahan Pustaka, Jakarta: Universitas Terbuka 
Nasution, M.N, 2001. Manajemen Mutu Terpadu (Total Quality Management). Ghalia Indonesia, Jakarta

Nasution. 2004. Manajemen Jasa Terpadu. Jakarta. Ghalia Indonesia

Ngo Vu Minh and Nguyen Huan Huu. 2016. The Relationship between Service Quality, Customer Satisfaction and Customer Loyalty: An Investigation in Vietnamese Retail Banking Sector. Journal of Competitiveness. Vol. 8, Issue 2, pp. 103 - 116, June 2016. ISSN 1804171X (Print), ISSN 1804-1728 (On-line), DOI: $10.7441 /$ joc.2016.02.08

Rangkuti, Freddy. 2015. Riset pemasaran. Jakarta, Gramedia Pustaka Utama

Republik Indonesia. 2007. Undang-Undang Republik. Indonesia Nomor 43 Tabun 2007 Tentang Perpustakaan. http://kelembagaan.pnri.go.id/Digital_Docs /pdf/about_us/official_archives/public/n ormal/PP\%20Nomor\%2024\%20Tahun $\% 2$ 02014.pdf, diakses pada tanggal 19 Oktober 2017

Riduwan. 2007. Metode Penelitian untuk Tesis. Bandung: Alfabeta

Singarimbun, Masri \& Sofian Effendi. 2006. Metode Penelitian Survai. Jakarta. Penerbit Pustaka LP3ES Indonesia.

Sri Astuti Pratminingsih, Christina Lipuringtyas, and Tetty Rimenta. 2013. "Factors Influencing Customer Loyalty Toward Online Shopping". International Journal of Trade, Economics and Finance, Vol. 4, No. 3, June 2013

Sufrin Hannan, Budi Suharjo, Rita Nurmalina dan Kirbrandoko. 2016. The Influence Of Perceived Quality, Perceived V alue, And Customer Expectation On Customer Satisfaction: An Empirical Study On Independent Surveyor Industry In Indonesia. I J A B E R, Vol. 14, No. 2 (2016): 603-613

Sugiyono. 2003. Metode Penelitian Bisnis. Alfabeta, Bandung.

Sugiyono. 2013. Metode Penelitian Kombinasi (Mixed Methods). Bandung: Alfabeta.

Sulistyo, Basuki. 1991. Pengantar Ilmu Perpustakaan, Jakarta :Gramedia Utama

Sulistyo, Basuki. 2010. Pengantar Ilmu Perpustakaan, Jakarta :Universitas Terbuka

Sulistyo, Basuki.1993. Pengantar Ilmu Perpustakaan. Jakarta, Gramedia Pustaka Utama.

Supriadi Setiawan. 2011. Loyalitas pelanggan jasa: Studi kasus bagamana rumah sakit mengelola loyalitas pelanggannya. Bogor: IPB Press. pp. 24-25

Sutardji dan Sri Ismi Maulidyah. 2006. Analisis Beberapa Faktor Yang Berpengarub Pada Kepuasan Pengguna Perpustakaan: Studi kasus di
Perpustakaan Balai Penelitian Tanaman Kacangkacangan dan Umbiumbian. Jurnal

Perpustakaan Pertanian Vol. 15, Nomor 2, 2006: 33-34.

Sutarsono, NS. 2005. Manajemen Perpustakaan : Suatu Pendekatan Praktik. Jakarta : Samitra Media Utama

Tamara, Leli. 2014. Pengarub Kualitas Pelayanan Terbadap Kepuasan Dan Loyalitas Pemustaka di Perpustakaan Nasional Republik Indonesia. Bogor : Institut Pertanian Bogor, Tesis.

Tjiptono, F. \& Chandra, G. 2011. Service, Quality \& Satification: Edisi 3. Penerbit Andi. Yogyakarta

Tjiptono, Fandy. 2005. Pemasaran Jasa. Edisi Pertama. Bayumedia, Malang. Umar, Husein. 2000.

Umar, Husein. 2008. Metode Penelitian untuk Skripsi dan Tesis Bisnis Edisi kedua. Jakarta: PT RajaGrafindo Persada.

Wantara, Pribanus. 2015. The Relationship between Quality of Service, Customer Satisfaction, and Customer Loyalty in the Library Service. International journal of Economics and Financial Issues Number 5 (Special Issue) 264-269

Wiyono G. 2011. Merancang penelitian Bisnis dengan Alat Analisis SPSS 17.00 dan Smart PLS 2.0. Yogyakarta : UPP STIM YKPN

Yamit, Zulian. 2002. Manajemen Kualitas Produk dan Jasa.Yogyakarta: Ekonesia.

Y. Nurendah dan M. Mulyana. 2013. Analisis Pengaruh Kualitas Pelayanan Perpustakaan Terhadap Kepuasan dan Hubungannya dengan Loyalitas Mahasiswa. Jurnal Ilmiah Manajemen Kesatuan Vol. 1 No. 1 . 2013 STIE Kesatuan ISSN 23377860

Zeithaml, Valarie, and Berry, Leonard. 2009. Services Marketing. New York : McGraw Hill 